\title{
In COVID-19, Unmet Needs of Nursing Students Participating in Limited Clinical Practice
}

\author{
Gie-Ok Noh \\ Assistant Professor, Department of Nursing, Konyang University, 158 Kwanjeodongro, Seo-gu, Daejeon, 35365, \\ South Korea
}

\begin{abstract}
Background: This study was conducted to identify unmet needs through qualitative research on students who have experienced clinical practice and alternative practice that are suddenly limited to COVID-19 situations.

Method: Qualitative research using focus group interviews involved five junior students with untact or limited clinical practice experience.

Finding: The unmet needs of nursing students were analyzed as four categories based on "lack of various media and visual materials" and "need to strengthen self-directed learning capabilities."

Conclusion: The results of this study suggested that nursing students who experienced untact or limited clinical practice experience are demanding education that utilizes various media and enhances self-directed learning, despite suffering from a lack of direct field experience and burden on tasks. Therefore, education programs should be developed to meet these needs.
\end{abstract}

Keywords: Clinical practice, Nursing students, Qualitative research, Unmet needs

\section{Introduction}

In the course of education for nursing students, clinical practice is an essential factor in inducing learning through self-regulation and reflection while experiencing practical clinical field ${ }^{1}$. In addition, the Korea Nursing Education Evaluation Institute suggests that nursing students conduct more than 1,000 hours of clinical practice during the curriculum ${ }^{2}$. However, with the spread of COVID-19 occurring from the end of 2019, many medical institutions do not permit practice or operate within a limited range ${ }^{3}$, alternative efforts are required for clinical practice.

Under the conditions of fendemic due to COVID-19, nursing education institutions take various measures such as in-school practice or simulation practice using online media to replace clinical practice ${ }^{4}$. However, it is not certain whether these alternatives can achieve the goals of integrating knowledge and practice, improving communication and decision-making skills, and acquiring time management skills ${ }^{5}$. There was also a positive aspect that if school practice was used effectively, it could receive immediate feedback from professors. However, the absence of direct contact with patients has a lower sense of reality about learning, and there are greater negative consequences, such as growing fear of future nurse roles ${ }^{6}$. Against this backdrop, it is necessary to identify what elements of learning students who actually participated in the replaced practical classes feel lacking.

Some prior studies ${ }^{7,8}$ have reported that simulation practice using virtual reality enables hands-on experience of patient experience. However, another alternative is needed because long-term simulation practices cannot be implemented throughout the practice that replaces clinical practice. In addition, some studies ${ }^{9}$, 10 reported that nursing students who did in-school 
practice experience expansion of knowledge through various clinical situations, but negative nurse images are formed and accept reality while experiencing chaos and skepticism. Clinical practice may serve as a partially negative experience, but it can be said to be an essential element of learning the actual field that nursing students face after graduation. In practice, which is inevitably applied as a substitute for clinical practice in a fendemic situation by COVID-19, it will need to be structured for the ultimate purpose of this learning.

Thus, in this study, we seek to identify unmet needs through qualitative research on students who have experienced clinical practice and alternative practice that are suddenly limited to COVID-19 situations. In addition, we would like to present a strategy to organize effective clinical practice alternatives through an understanding of the unmet needs of students who are participants in learning.

Methods

Study design: This study is a qualitative survey study attempted to identify the unmet needs caused by limited clinical practice participation. This study conducted a focus group interview method that has the advantage of collecting data from various perspectives through interactions between group members in deriving experiences by retrospect ${ }^{11}$.

Participants: The subject of this study is a junior nursing student who has completed a clinical practice course for one year. Participating students had experience with untact practice during the first semester due to COVID-19, and limited clinical practice during the next semester. Five nursing students participated in the study through the recruitment process.

Data Collection: The data collection was conducted through an interview in January 2021. In order to give study participants time to think about the topic, questions were organized and delivered in the form of questionnaires three days before the interview (Table 1). All questions were open-ended, and the key questions were "Which of untact or limited clinical practices did you experience?" or "What are your requests for untact or limited clinical practices?".

Interviews were conducted in small classrooms within the school, and were arranged to sit around a round table so that they could talk face to face with each other. The interview took about 90 minutes, and two recorders were recorded in a place where all participants' voices could be heard.

Table 1: Questions for focus group interviews

\begin{tabular}{|c|c|}
\hline Categories & Contents \\
\hline Opening & 1. Would you introduce yourself to each participant? \\
\hline Transition & 2. What kind of clinical practice did you carry out after COVID-19 outbreak? \\
\hline Key & $\begin{array}{r}\text { 3. What were your expectations for clinical practice? } \\
\text { 4. Which of untact or limited clinical practices did you experience? } \\
\text { 5. What are your requests for untact or limited clinical practices? }\end{array}$ \\
\hline
\end{tabular}

Data Analysis: Within two weeks of the focus group interview, the recording was completed. Data analysis was done using Giorgi ${ }^{12}$ data analysis method. The analysis process was conducted in three stages, in which the transcription was comprehensively identified, the similar meaning code was collected to classify units, and the measuring units were transformed into the closest academic representation. 


\section{Results}

In this study, an analysis of the unmet needs of nursing students who have experienced untact or limited clinical practice has identified four categories and collections of eight themes (Table 2).

Table 2: Categories and theme clusters

\begin{tabular}{|c|c|}
\hline Categories & Theme clusters \\
\hline $\begin{array}{c}\text { Disappointment of lack of practical field } \\
\text { experience }\end{array}$ & $\begin{array}{c}\text { - Disappointment of lack of experience in rapport } \\
\text { - Disappointed with the lack of experience in various cases }\end{array}$ \\
$\begin{array}{c}\text { Feeling burdened by heavy hands-on tasks } \\
\text { Lack of various media and visual materials }\end{array}$ & $\begin{array}{c}\text { - Heavy task that builds up every day } \\
\text { - Requirements for audio-visual materials, such as videos }\end{array}$ \\
\hline $\begin{array}{c}\text { Need to strengthen self-directed learning } \\
\text { capabilities }\end{array}$ & $\begin{array}{l}\text { - Need for the variety of hands-on time configurations } \\
\text { - Strategies to improve self-directed learning during class }\end{array}$ \\
\hline
\end{tabular}

\section{Categories 1: Disappointment of lack of practical} field experience:

The students performed various activities such as virtual case analysis and major disease literature examination with untact or limited practice. However, the students were regretting that they could not experience hands-on learning through direct contact with patients and the experience of rapport formation with patients.

"I actively participated in learning through virtual cases, but I was very sorry that I didn't have a chance to form rapport with real patients." (participant 2)

\section{Categories 2: Feeling burdened by heavy hands- on tasks}

The nursing students were given more tasks to meet their practice time in the untact or limited clinical practice process. In addition, students felt a lot of pressure on the task as more tasks were required to write handwritten notes to enhance the sincerity of the task.

"I was physically challenged because I had to write my own assignment every day for every day." (participant 1, 2)

\section{Categories 3: Lack of various media and visual materials}

The nursing students were asked to provide more visual materials such as videos and run various programs because they had to fill up the time they practiced in the field with other activities.

"I thought programs such as virtual simulation and video training materials were much more needed. ' (participant 3, 5)

\section{Categories 4: Need to strengthen self-directed} learning capabilities

The nursing students realized that they needed selfdirected learning capabilities as they had more time to learn on their own without field leaders in the untact or limited clinical practice process.

"It wasn't easy to concentrate on myself. I would like you to tell me how to help me with effective selfdirected learning." (participant 4) 


\section{Discussion}

In this study, it was intended to identify the unmet needs of nursing students who suddenly experienced untact or limited clinical practice. Unmet needs derived from the results of the study were 'lack of various media and visual materials' and 'need to strengthen selfdirected learning capabilities'.

First, the category 'Disappointment of black of practical field experience' showed that despite various alternative efforts, it was difficult to fully complement the actual site. Direct clinical on-site hands-on participation can not only improve the quality of nursing students' learning but also increase awareness of their responsibilities as future nurses ${ }^{13}$. Kim et al. ${ }^{6}$ reported that group activities or simulations were used when clinical practice was replaced by in-school practice, but did not meet the expectations of participants due to differences in field experience. Therefore, close cooperation with hospitals will be needed to provide maximum field experience, and the replacement practice time will require the development of complementary programs to enhance the sense of field experience.

The second category, 'Feeling Burden by Heavy Hands-on tasks', expresses difficulties in the tasks given to students in order to produce evidence of actual practice-time operations ${ }^{6,14}$. To solve these students' difficulties, technical approaches need to be attempted, such as developing a computer program that can be used continuously during the practice time and proving the practice time.

The third and fourth categories are actually the results that correspond to factors that participants feel lacked in non-face-to-face or limited clinical practice $\mathrm{Ha}$ $\&$ Lee $^{15}$ suggested that alternative practices in schools were applied using online group discussions, problembased learning, and case-based learning, and that the most influential factor in problem-solving skills was the motivation. Similarly, participants in this study called for education that could enhance self-directed learning. It is required to construct a program to achieve performance step by step through self-directed learning ${ }^{16,17}$, which is thought to result in reinforcement of the learning motivation ${ }^{18}$. The nursing students who participated in this study asked for more visual materials and media utilization. In many prior studies ${ }^{19-21}$ conducted on nursing college students, the effects of learning using video clips were presented. There is management of field leaders during practice at the actual clinical field, but in the case of untact or alternative practice, students themselves have to use their time during the given practice time, so strategic development such as video is even more required.

In this study, there is a limit to the generalization of the results of the study because the experience of a minority of participants was collected on the basis of retrospect and the data was analyzed. In situations where COVID-19 persists, iterative studies analyzing the experiences and needs of untact learners need to be conducted. Based on the results of this study, we also propose to conduct research on program development that can reduce gaps with clinical sites, systematically change tasks for practice time management, and induce self-directed learning using various media.

Source of Funding: Self-funding

Ethical Clearance: Not required

Conflicts of Interest: None

\section{References}

1. Filice S, Tregunno D, Edge D, Egan R. Re-imaging clinical education: the interdependence of the selfregulated clinical teacher and nursing student. International Journal of Nursing Education Scholarship. 2020;17(1):1-12.

2. Korean Accreditation Board of Nursing Education [Internet]. A college handbook for nursing education certification evaluation in the first half of 2021. [2021 April 10]. Available from https:// www.http://www.kabone.or.kr/notice/list/view. do?num $=756$

3. Kang J. Simulated nursing practice education in the on-tact age: a mixed methods case study. Journal 
of Learner-Centered Curriculum and Instruction. 2020;20(18):937-57.

4. Song YM, Effects of an online psychiatric and mental health nursing practice program on the social and emotional competence, counseling selfefficacy, and communication competence among nursing students. Journal of Learner-Centered Curriculum and Instruction, 2020;20(19):271-290.

5. Lofmark A, Wikbald K. Facilitating and obstruction factors for development of learning in clinical practice: A student perspective. Journal of Advanced Nursing. 2001;34(1):43-50.

6. Kim HS, Kim EM, Lee DS. A study on the experience of nursing student's clinical education in school practice: Focused on psychiatric nursing practice. Journal of Korea Academia-Industrial cooperation Society. 2021;22(2):169-178.

7. Lim S, Yeom YR. The effect of education integrating virtual reality simulation training and outside school clinical practice for nursing students. Journal of Convergence Information Technology. 2020;10(10):100-108.

8. Kang JY. Simulated nursing practice education in the ontact age: A mixed methods case study, instructor-learner interaction, and class satisfaction of nursing students. Journal of Learner-Centered Curriculum and Instruction. 2020;20(18):937-957.

9. Kim SH, Lee EM. Experience of the gap between classroom based and clinical based learning for n-ursing practice among Korean nursing student. Journal of Learner Centered Curriculum and Instruction. 2017;17(2):19-42.

10. Song HS, Lim SH. A phenomenological study on the first clinical practice experience of nursing student. Asia-pacific Journal of Multimedia Services Convergent with Art, Humanities, and Sociology. 2019;9(5):533-543.

11. Kruger RA, Casey M. Focus groups: A practical guide for applied research. 5th ed. California: Sage publications. 2015, 1-252.

12. Giorgi A. The descriptive phenomenological method in psychology: A modified Husserlian approach. 2009, Pittsburgh, PA: Duquesne University Press.

13. Strand K, Tveit B. Planning and implementing quality improvement projects in clinical practice: Third-year nursing students' learning experiences. Journal of Clinical Nursing. 2020;29(23):47694783.

14. Kim SN. The contents analysis of nursing student's perception about on-line lecture. Journal of Learner-Centered Curriculum and Instruction. 2020;20(17):477-491.

15. Ha YK, Lee YH. In COVID-19, factors affecting the problem-solving ability of nursing students participating in alternative clinical practicum. Journal of Learner-Centered Curriculum and Instruction. 2021;21(2):989-1006.

16. Park JH. The effect of self-leadership program for nursing students on empowerment, selfdirected learning, and happiness. Journal of the Korea Academia-Industrial cooperation Society. 2019;20(7):61-67.

17. Kim SH, Gang MH. The effect of flipped learning based nursing process education on self-directed learning ability and academic achievement of nursing students. Journal of the Korea Entertainment Industry Association. 2020;14(7):363-372.

18. Lee JS, Kim SH. The relationship of learning motivation, self-directed learning ability and critical thinking disposition of nursing student. Journal of Learner-Centered Curriculum and Instruction. 2020;20(23):937-952.

19. Kang SA. Convergence study about the effects of pre-learning and role learning using video on self-regulated learning of nursing students in fundamental nursing practice education. Journal of the Korea Convergence Society. 2018;9(5):247256.

20. Yoon YS. Effect of radiation safety management education with the use of visual-auditory materials for nursing students, The Journal of Korean 
Nursing Research. 2019;3(2):1-12.

21. Park J. The effects of clinical convergence selfdirectedness practice learning program on self-
Medico-legal Update, October-December 2021, Vol.21, No. $4 \mathbf{1 5 5}$ directedness and competency in fundamental nursing skills in undergraduate nursing students. Journal of the Korea Convergence Society. 2016;7(4):51-58. 